\title{
Cervical Spinal Injuries and Risk Assessment
}

\author{
Mary E. Blackmore, Tarun Goswami and Carol Chancey
}

Additional information is available at the end of the chapter

http://dx.doi.org/10.5772/50588

\section{Introduction}

As of mid 2001, out of the 34000 spinal injuries that took place in the previous year, over half (55\%) were cervical spine injuries [18]. Additionally, out of all the cervical spinal injuries incurred by patients in the United States every year, $15 \%$ of those injuries are fatal [7]. Motor vehicle crashes are the leading cause of death for persons under 45 years of age, and the number one cause of head and spinal cord injury [1]. This study compiles and analyzes data that may be used to assess risk of cervical injury.

The cervical spine is a very complex anatomical structure. Any neck injury can have debilitating, and sometimes life threatening consequences. Although spinal cord injuries vary significantly from the injuries of the vertebral column, they result from structural deformities and were therefore studied prior to this analysis [21]. For both spinal cord injuries and vertebral body fractures, motor vehicle accidents are the most common causes of neck injuries in both Canada and the United States (Figure 1). Out of the 1.4 million annual American spinal cord injuries, approximately 280,000 of those are motor vehicle induced. One out of every five drivers are involved in a traffic accident each year [1]. Figure 1 illustrates the most common mechanisms for cervical spine injuries. Another interesting aspect is the increase in violence, which in turn could impact the number of violence related spinal injuries and incidents (shooting, stabbing, etc.) [21].

Sports and leisure activities account for a significant amount of neck trauma. They can be broken down by both the activities most likely to cause injury, as well as the injuries accounted for in specific sports. Understanding what particular actions and motions within each activity actually contribute to the risk of injury, has helped improve sporting equipment and decrease the number of neck injuries associated with various sports. Table 1 lists the most common leisure activities associated with neck injuries [20]. Diving and surfing involve more injuries than football (Table 1). This is most probably because football has grown in popularity since 1989 , when this data was originally compiled. 


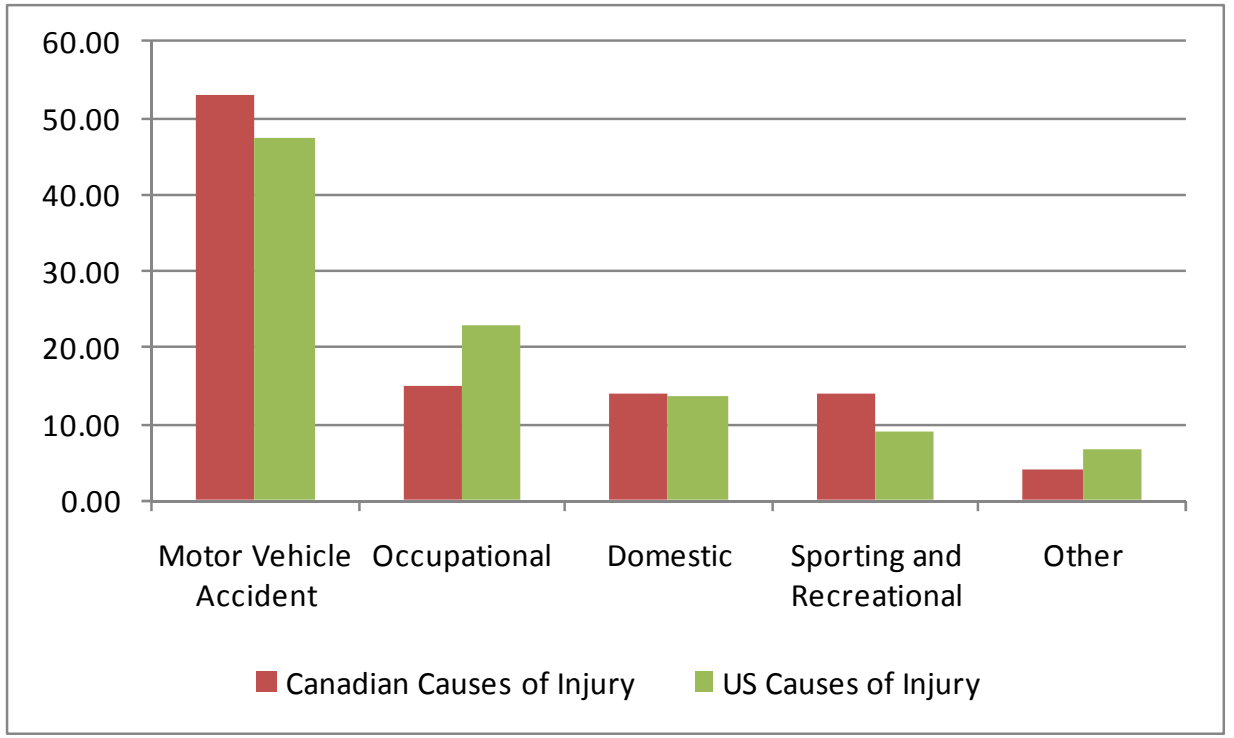

Figure 1. Frequency of Activities Causing Cervical Injuries, in Percentage [7]

From Table 1, it can be seen that many common everyday activities offer the potential for serious injury. In diving, fractures and dislocations are the most commonly seen. Not only are the diver's form and function important, but depth of water, angle of entry and head velocity also prove crucial to injury severity. Degrees of participation within the various sports also play a role in the frequency of injury. Today, more athletes participate in football, making the likelihood of injury higher than it was in 1989.

\begin{tabular}{|c|c|c|}
\hline Cane of hisy & Nuriler & linies [x] \\
\hline Diving & 82 & 54 \\
\hline Football & 16 & 11 \\
\hline Gymastics & 5 & 3 \\
\hline Snow Skiing & 5 & 3 \\
\hline Surfing & 29 & 19 \\
\hline Track and Field & 3 & 2 \\
\hline Trampoline & 2 & $\mathbf{1}$ \\
\hline Water Skaing & 7 & 5 \\
\hline Whestling & 3 & 2 \\
\hline Total & 152 & \\
\hline
\end{tabular}

Table 1. Sports Activities Causing Cervical Spinal Injuries 


\section{Research background: Analysis of cervical spinal tolerances and injuries}

With motor vehicle accidents being the leading mechanism behind both spinal cord and vertebral fracture injuries, significant research has focused on improving the design and safety of automobiles [14]. Vertebral fractures can occur at any level to any degree, and can be caused by various types of loading. Figure 2 illustrates the frequency of injury to various levels of the cervical spine as well as the type of loading that causes that injury.

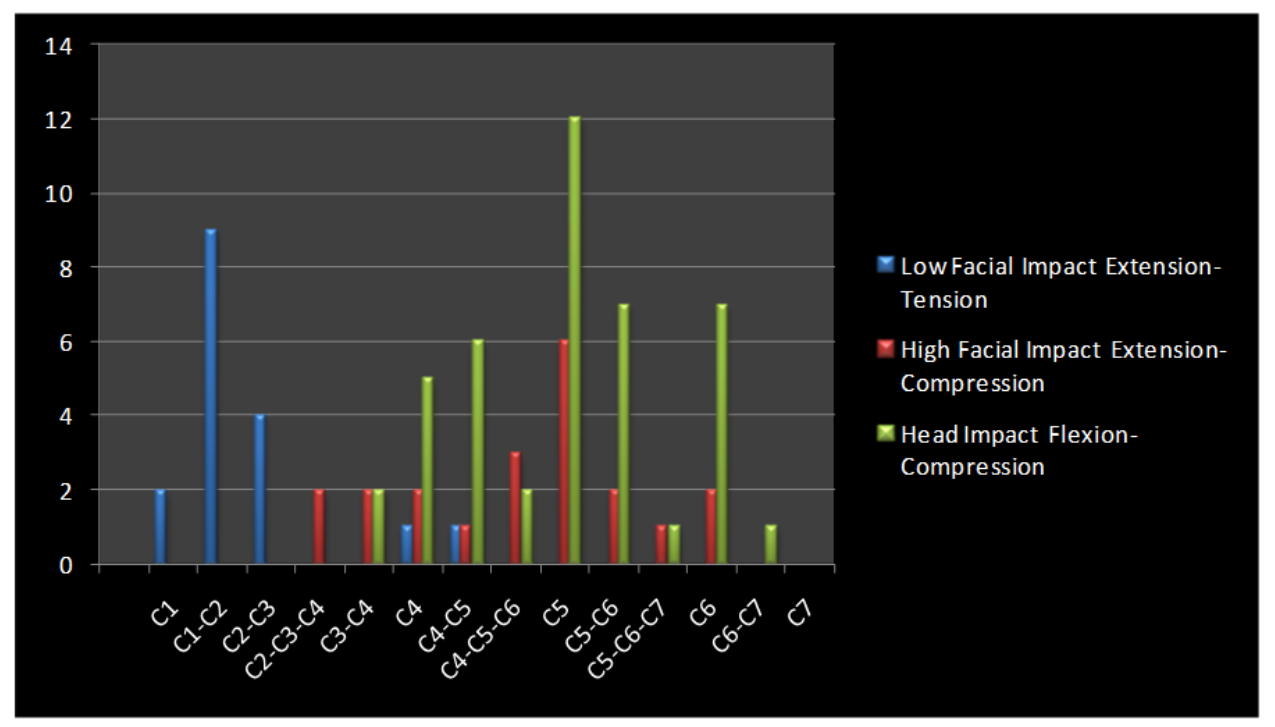

Figure 2. Frequency of Fractures per Level, Based on Type of Impact Loading

This data is also represented by use of the Abbreviated Injury Scale (AIS). Especially in the case of automobile and motorcycle accidents, the victim is usually injured because of some form of head contact with another object. Many factors contribute to the severity of the injury: position of the head and neck, the impact site, the nature of the impacted surface and the direction of the cervical spine loading. Determining the relationship between all of these variables is very complex and until recently has been based on frequency of occurrence data. Table 2 is a summary of the AIS scale characteristics. Figure 3 illustrates the amount of injuries that occurred in over 100 automobile accidents, in which a passenger attained a neck injury of some degree [25]. The degree of the injury is indicated by the AIS score.

With respect to frequency, the $5^{\text {th }}$ and $6^{\text {th }}$ vertebrae of the cervical spine see the most injury, and have the most critical injuries (AIS 5). This is the most significant score one can achieve and still survive, meaning that the ability to minimalize the chance of injury through improved vehicles and vehicle interior is crucial to assessing and preventing risk. 


\begin{tabular}{|c|c|}
\hline AlS Score & Injury \\
\hline & \\
\hline 1 & Minor \\
\hline 2 & Moderate \\
\hline 3 & Serious \\
\hline 4 & Severe \\
\hline 5 & Critical \\
\hline 6 & Unsurvivable \\
\hline
\end{tabular}

Table 2. AIS Scoring Details [12]

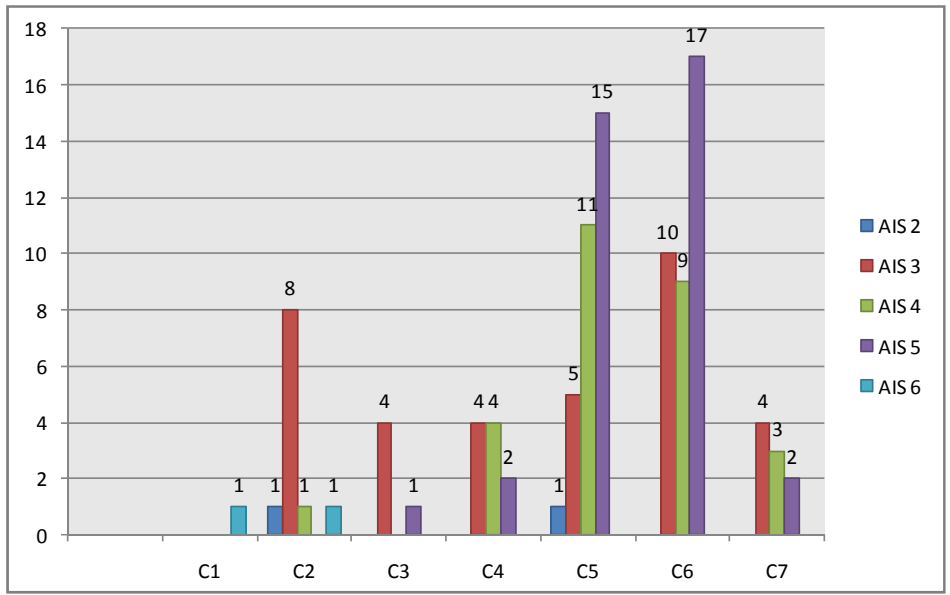

Figure 3. Automobile Injuries by Cervical Spinal Level and Their Associated AIS Scores

To assess the potential for injury, the loads that the cervical spine can withstand during various activities must first be understood. This can be broken down into the type of loading seen during the various activities. There are 5 main types of loading incurred by the cervical spine: Flexion-Extension, Compression, Tension, Torsion and Horizontal Shear. The main injury mechanisms are shown in Figure 4, while all are described in succeeding sections.

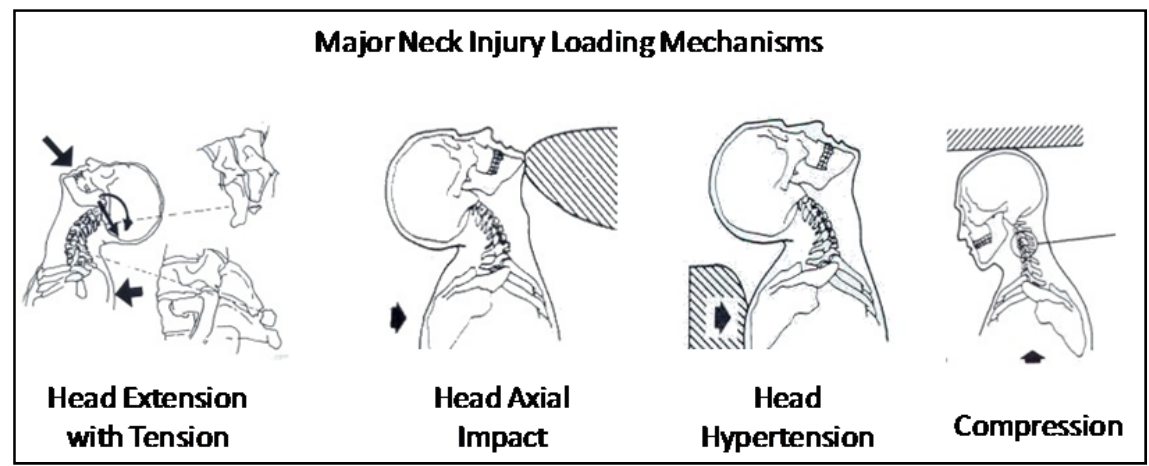

Figure 4. Injury Mechanisms of the Cervical Spine 


\subsection{Flexion-extension}

A lower bound for the risk of injury of the neck under flexion-extension is based on the bending moment at the occipital condyle. For extension, noninjurious loading occurs at 35 $\mathrm{ft}-\mathrm{lbs}(47.3 \mathrm{Nm})$, with ligamentous injury occurring above $42 \mathrm{ft}-\mathrm{lbs}(56.7 \mathrm{Nm})$. For flexion, pain can be felt at a load of $44 \mathrm{ft}-1 \mathrm{bs}(59.4 \mathrm{Nm})$ and the risk of significant structural damage occurs around and above $140 \mathrm{ft}-\mathrm{lbs}(189 \mathrm{Nm})$. Bending moments of $24 \mathrm{Nm}$ and resultant forces of $130 \mathrm{~N}$ can be felt without injury, but anything beyond that will most likely result in injury $[10,12,15]$.

\subsection{Compression}

This is the most researched type of loading, as a large amount of data can be found on compressive load analysis until failure is reached. The type of axial loading and the degree of constraint imposed on the contacting surfaces causes the results to vary among investigators. It has however been proven that compression-flexion and compression-extension injuries occur under smaller axial loads than pure compressive injuries. Bilateral facet dislocations can occur at loads of $1720 \pm 1230 \mathrm{~N}$, with flexion injuries occurring at approximately $2000 \mathrm{~N}$. When dealing with pure compression, injuries have been reported under loads of $4810 \pm 1290 \mathrm{~N}$ of loading. The average peak head and neck loads that can be reached before structural injury occurs are $5.9 \pm 3.0 \mathrm{kN}$ and $1.7 \pm 0.57 \mathrm{kN}$, respectively [10, 14].

\subsection{Tension}

Tension loading is not a commonly studied area of research. Past studies have indicated that the cervical spine has a tensile loading tolerance of $1135 \mathrm{~N}$. With respect to automobile accidents, the average cranial accelerations are usually between 40 and $50 \mathrm{~g}$ [11]. This results in an estimated traction load of the Atlas (C1) of $1600-2000$ N [3]. These types of loads produce disc damage, joint capsule tears and skull and vertebral fractures. The mean force at failure of intervertebral discs is $581 \pm 220 \mathrm{~N}$, but much still needs to be identified with respect to the amount of tensile force the vertebral bodies, and the entire cervical spine can withstand [19].

\subsection{Torsion}

The estimated lower bounds of axial torsional tolerance are between $13.6 \pm 4.5 \mathrm{Nm}$ and 17.2 $\pm 5.1 \mathrm{Nm}$ [13]. This amount of torque produces upper cervical spinal injuries. It has also been estimated that the cervical spine can withstand approximately $114 \pm 6.3^{\circ}$ of rotation before injury occurs $[6,24]$.

\subsection{Horizontal shear}

Another area not too commonly researched is the amount of horizontal shear needed to produce cervical spinal injury. Most of this research is conducted to learn more about the 
mechanisms that cause occipito-atlantoaxial injuries. Transverse ligament rupture has been seen to occur at a load of $824 \mathrm{~N}$, with anterior shear of the atlas [5]. Odontoid fractures reportedly occur at $1510 \pm 420 \mathrm{~N}$ of shear force [4]. Additional, higher tolerances have been reported up to $5500 \pm 2500 \mathrm{~N}$ when the shear force is applied at the chest [2].

\section{Methods - Assessing the probability of injury}

In this section graphical presentation of risk of injury presented. Envelops pertaining to risk free and high risk injury needs to be established. Based on the data compiled here, and by others [14] the succeeding curves have been developed to establish the amount of existing risk associated with various types of cervical spinal loading. The first set of curves in Figure 5 illustrate the tolerance of tensile loads of 5 different human body types, (mannequins were used to test and extract data for each of these body types), based on the amount of time the load is applied. The Hybrid III Family of Mannequins is a well established group used for testing the effects of various types of loading on different sized bodies. Within this family are five mannequins: (i) A 3 Year Old, (ii) a 6 Year Old, (iii) a Small Adult, (iv) a Midsize Adult and (v) a Large Adult. Table 3 displays the characteristics of each particular mannequin.

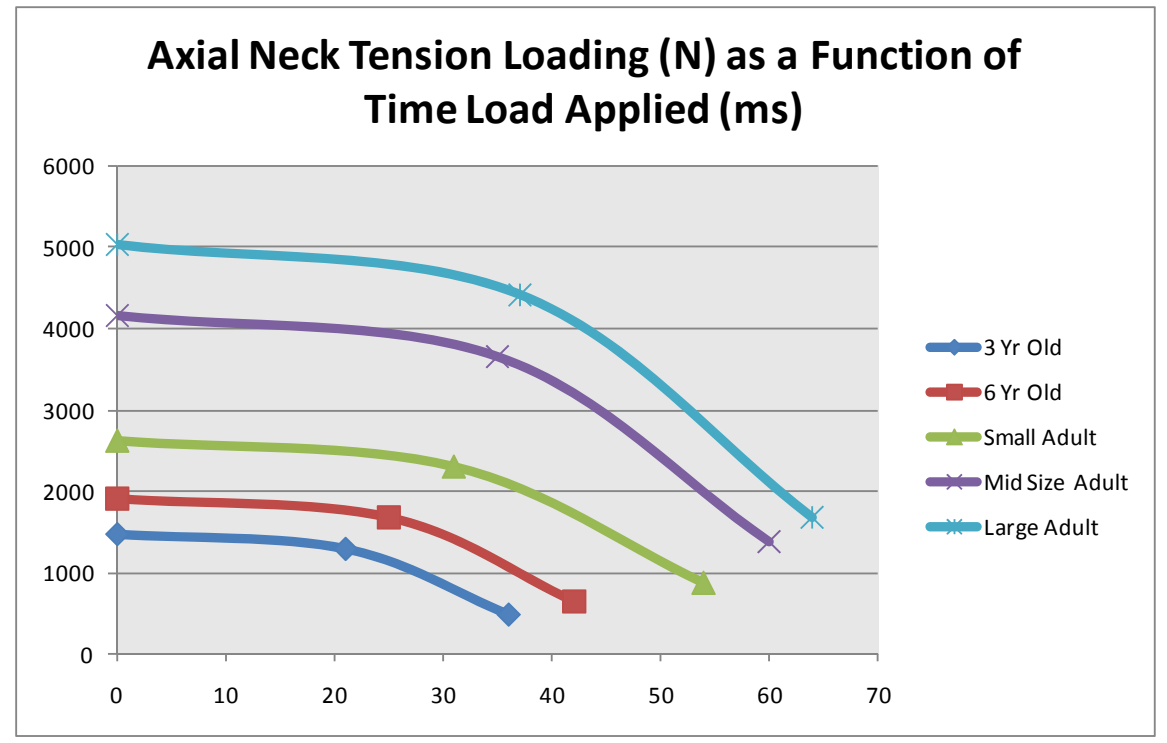

Figure 5. Tension Loading of Five Different Body Types Retrieved from Dummy Data [13]

No height is given for the 3 and 6 year old mannequins because their development was based largely in part on estimates and approximations. This remains a difficult parameter to analyze because so little data exists on the effects of accidents on children. Figure 5 displays the Axial Tension (Newtons) Tolerance of the mannequins with respect to time (milliseconds). 
Anything above each individual curve in Figure 5 indicates the potential for significant neck injury due to tension loading, while anything below indicates that significant neck injury due to loading is highly unlikely. Compression and shear data was analyzed and compiled in a similar fashion, to develop the curves in Figures 6 and 7, respectively. Anything above each individual curve indicates the potential for significant neck injury due to compression loading, while anything below means that significant neck injury due to loading is highly unlikely.

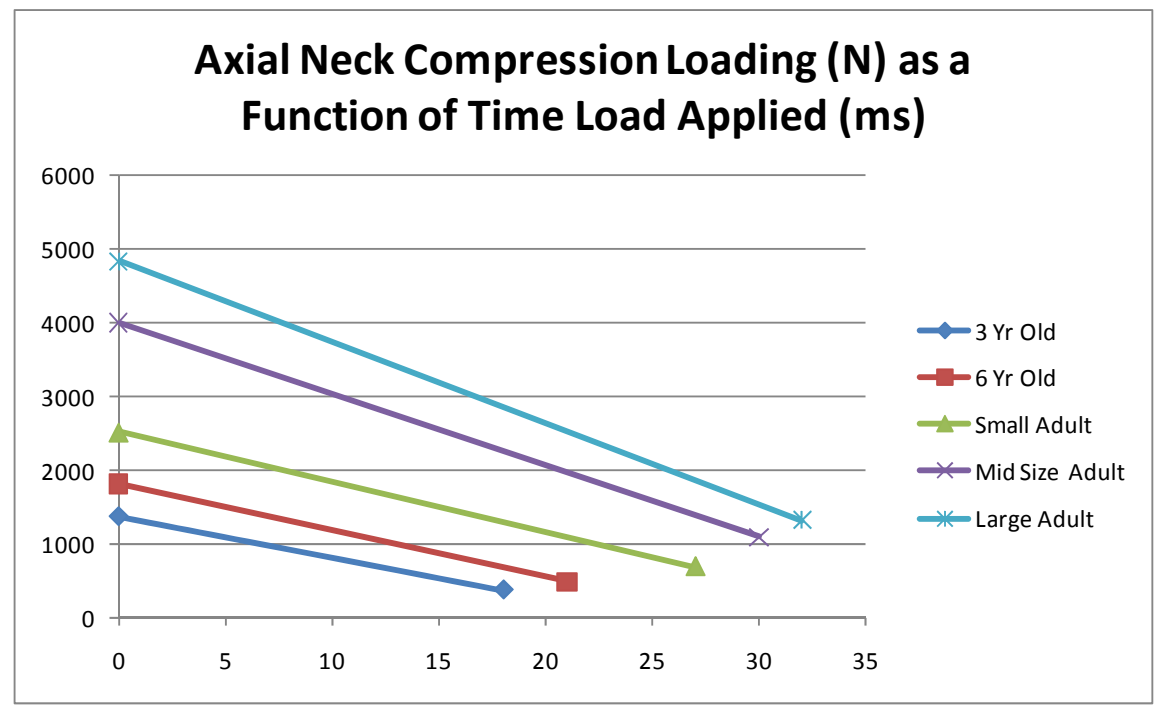

Figure 6. Compression Loading on the Neck [13]

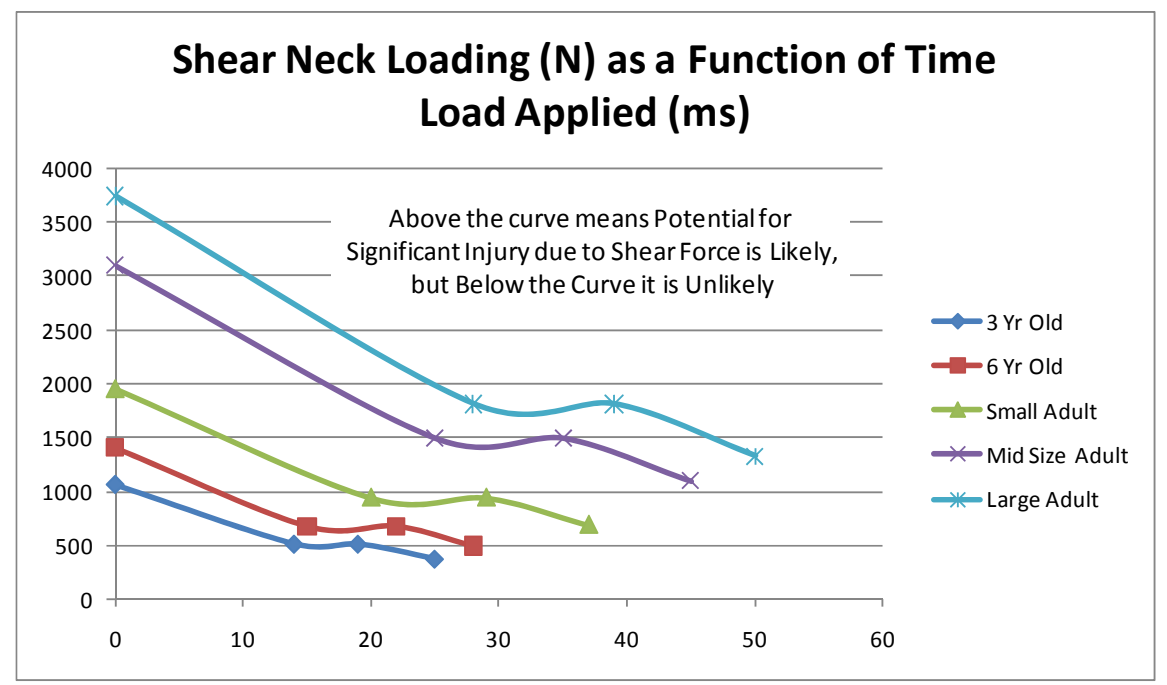

Figure 7. Shear Neck Loading Data [13] 
Each of the curves for compression, tension and shear loading were analyzed. From these curves, specific data points were extrapolated and both standard deviations and standard error for each point were calculated. The extrapolated data for compression, tension and shear loading are illustrated in Figures 8, 9, and 10 respectively.

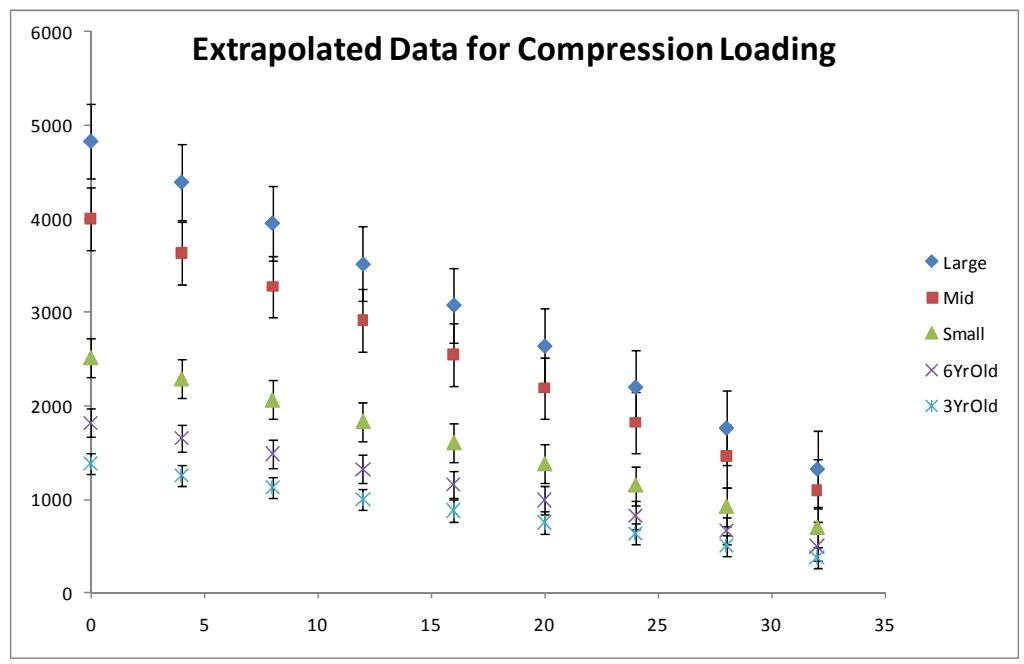

Figure 8. Extrapolated Compression Loading Data

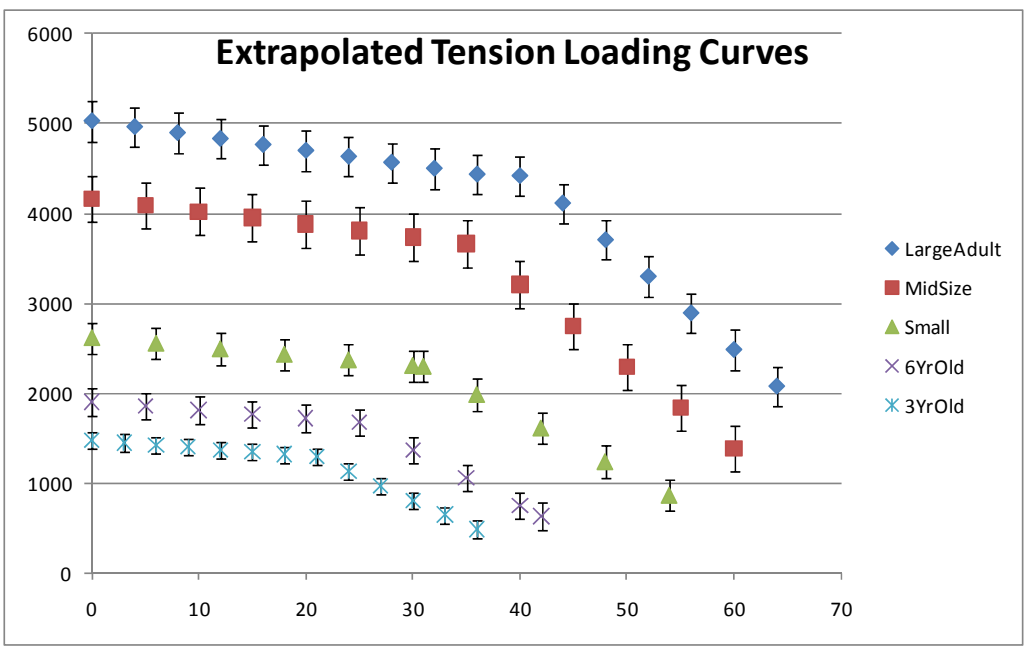

Figure 9. Extrapolated Tension Loading Data

From the standard deviations, ranges of loading were developed for each of the following three scenarios: (i) no injury or minor injury will occur, (ii) A moderate injury is likely to occur and (iii) an unsurvivable injury is likely to occur. For the purposes of comparison, no/minor injury in this analysis refers to an injury that rates from 0 to 1 on the AIS scale. 
Similarly, a moderate injury refers to AIS 2-5 and an unsurvivable injury, to AIS 6. These three scenarios were plotted for compression, tension and shear loading for the five different body types previously mentioned.

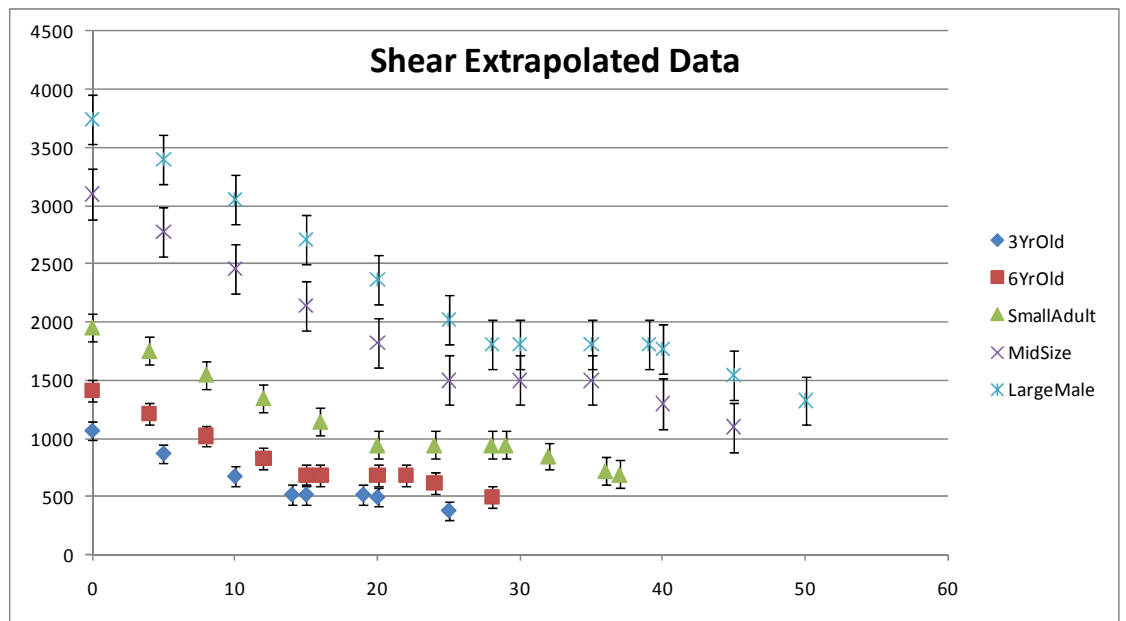

Figure 10. Extrapolated Data for Shear Loading

\section{Probability of risk}

With the assistance of an Excel Add-In called RiskAmp, numerous Monte Carlo Simulations were set up to study the probability of the five different dummy types being exposed to various compressive, tensile and shear forces. Because of their reliance on repeated computation of random or pseudo-random numbers, these methods tend to be used when it is unfeasible or impossible to compute an exact result with a deterministic algorithm [22]. Applied forces were randomly generated for 1000 simulations. The simulation means and standard deviations were studied. Ranges of force values known to produce responses in the 3 "Injury Zones" were tested against the simulation means to determine the probability of exposure to the varying degrees of compressive, tensile and shear forces.

The risk of injury of being exposed to a force that would place the dummy in each of the three previously discussed injury zones (No Injury Likely, Moderate Injury Likely and Unsurvivable Injury Likely) were developed thereafter.

\section{Results}

Axial loading, whether tension or compression, can pose a significant risk of injury as seen by the ISO-13232 (Figure 11) testing and analysis procedures [23]. Figure 12 shows the axial neck force time responses as measured in a laboratory head impact test and computer simulation. In figure 12, it can be seen that after only 5 milliseconds, the largest compressive force is exerted on the neck of the rider. After only 15 milliseconds, the rider is then exposed to the highest tensile forces; a direct result of the neck rebounding from compression. And 
finally, after approximately 30-35 milliseconds, the reactive forces level off. This plot illustrates that the majority of force exposure in impact scenarios occurs within the first 30 milliseconds. It is thus important to focus on the risk of injury during that time frame.

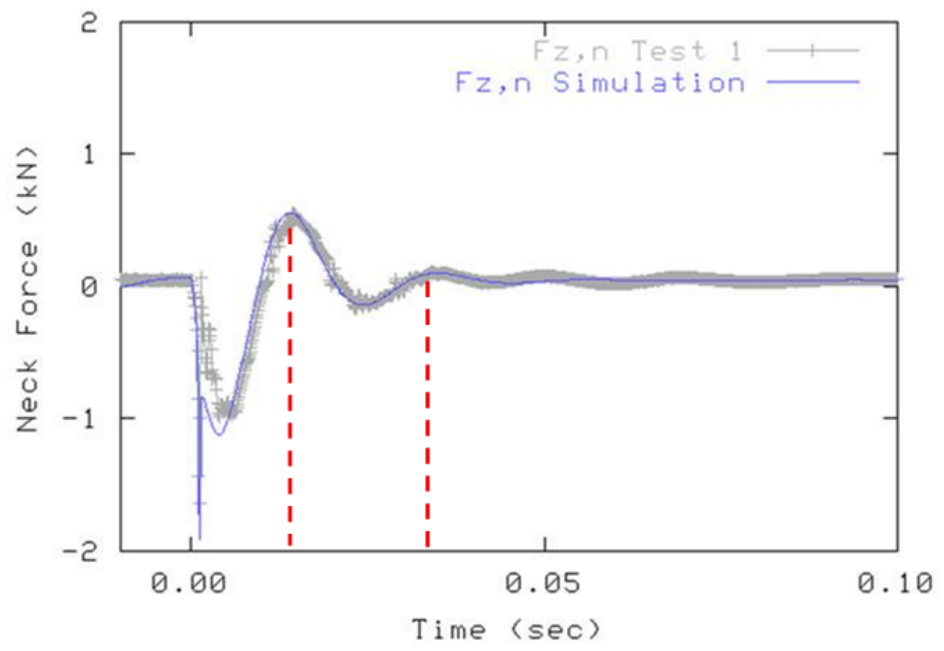

Figure 11. ISO-13232 Axial neck Force Time Responses Measured in a Laboratory Head Impact Test and Computer Simulation [23]

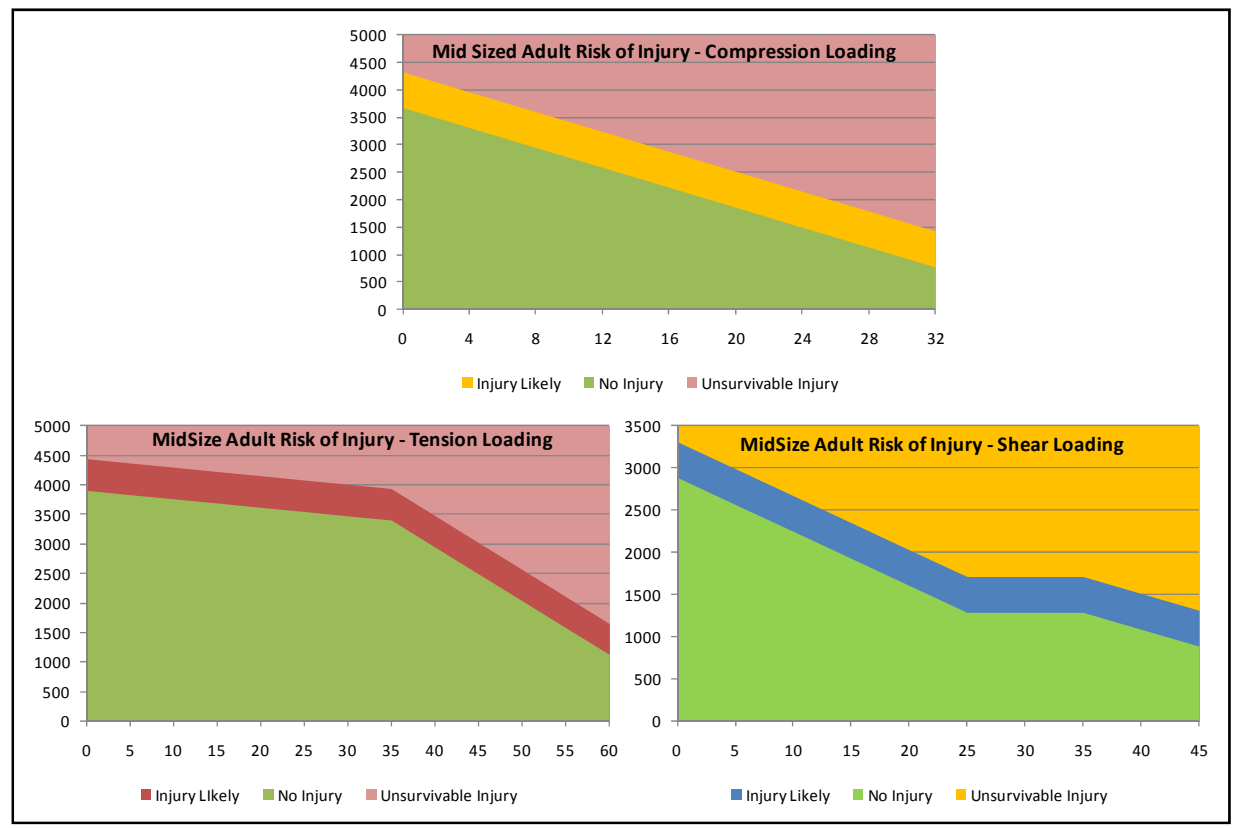

Figure 12. Mid Size Adult Risk of Injury Criteria 
Trends are apparent when the five mannequins are all compared under the same type of loading. Under compression, they all exhibit a linear tolerance to loading. For the mid size adult, an instantaneous force between 3700 and $4300 \mathrm{~N}$ indicates a significant injury is likely. Anything above $4300 \mathrm{~N}$, illustrates a higher risk of an unsurvivable injury. The linear descending trend remains apparent throughout the first 32 milliseconds of force duration. At 32 milliseconds, it only takes a force between $1000 \mathrm{~N}$ and $1600 \mathrm{~N}$ to expose the adult to a risk of significant injury. At $1600 \mathrm{~N}$, applied for $32 \mathrm{~ms}$ means that an adult is at very high risk of an unsurvivable injury. As the applied compressive load increases with respect to time, the probability of injury linearly increases.

When exposed to tension, a descending, "bi-linear" relationship is seen. Instantaneous forces below $3900 \mathrm{~N}$ pose no significant risk of injury. Anything between $3900 \mathrm{~N}$ and $4500 \mathrm{~N}$ indicates a considerable risk of injury. Finally anything above $4500 \mathrm{~N}$ illustrates a dangerous risk of unsurvivable injury. A slightly decreasing linear trend occurs between 0 and $35 \mathrm{~ms}$. At this point in load duration, the linearity changes, the decreasing slope becomes aggressive and the risk of injury becomes more severe. At $35 \mathrm{~ms}$, it takes between $3500 \mathrm{~N}$ and $4100 \mathrm{~N}$ to see a significant risk of injury, but as time increases to 60 milliseconds, only a force of $1100 \mathrm{~N}$ is needed to generate a significant risk of moderate injury. In the first half of the plot, a very gradual decrease in load tolerance with respect to time is evident, but after a load duration of 35 milliseconds, the slope of linearity significantly decreases, indicating that a much higher probability of injury exists.

The shear loading relationship increases in complexity, as it is "tri-linear" in nature. The first third of the plot demonstrates a strong descending linear relationship. An instantaneous force of $2900 \mathrm{~N}$ poses a good chance for a moderate to severe injury. Any force above $3300 \mathrm{~N}$ instantaneously applied shows a very high risk for an unsurvivable injury. Initially, as with all the mannequin types, a gradual decrease in shear loading tolerance is evident. After approximately 25 milliseconds, the tolerance to shear force plateaus. From 25 to 35 milliseconds of load duration, a force of only $1300 \mathrm{~N}$ is needed to substantiate the chance for a moderate injury. Anything above $1800 \mathrm{~N}$ indicates that the risk of an unsurvivable injury occurring is quite high. Any load duration beyond $35 \mathrm{~ms}$, sees another decreasing linear trend. It is at the point of $45 \mathrm{~ms}$, that a force of only $900 \mathrm{~N}$ is needed to pose significant threat of injury on the neck. This curve behavior illustrates the neck's ability to resist twisting just prior to complete fracture.

Because the probability of injury trends for the five mannequins were similar, only the loading curves for the mid size adult are shown (Figures 12).

Injury due to shear loading seems to happen at much smaller loads for all body types than injuries caused by the other types of loading. For example, the 3 year old experiences instantaneous injury from a tension or a compression load of approximately $1400 \mathrm{~N}$; however the shear load needed to induce injury is only approximately $1000 \mathrm{~N}$. As age and physique increase, a body's tolerance to loading also increases. For example, the 6 year old mannequin does not experience instantaneous injury due to compressive 
loading until a load of $1700 \mathrm{~N}$ is applied. This is higher than the load that a 3 year can forebear, but much less than the $4400 \mathrm{~N}$ needed to cause compressive injury to a large adult.

The risk of injury has been presented graphically with respect to the types and magnitudes of forces that are more likely to cause injury, based on age and load duration. The succeeding tables depict the average probability of injury, based on body and loading types. For each Monte Carlo Simulation performed, probability of injury was calculated for a variety of time steps, starting with 0 milliseconds and concluding with a time value known to cause serious injury (i.e. for compressive loads, a concluding time of 32 milliseconds was used for all five mannequin types). The probabilities listed in Tables 3-6 were calculated by averaging the results of the Monte Carlo Simulations for each time step. These values were averaged for the purpose of data consolidation. As can be seen in Tables 4-6, the bigger the mannequin, or human body type, the higher the probability that no injury will occur, and the less likely that an unsurvivable injury will take place.

\begin{tabular}{|lccc|}
\hline \multicolumn{3}{c}{ Hybrid III Family } \\
\cline { 2 - 4 } Mannequin & Height & \multicolumn{2}{c|}{ Weight } \\
\cline { 2 - 4 } ( Yr Old & (ft, in) & (lbs) & (kg) \\
6 Yr Old & -- & 33 & 15 \\
Small Adult & -- & 47 & 21 \\
Midsize Adult & $5^{\prime} 0^{\prime \prime}$ & 110 & 50 \\
Large Adult & $5^{\prime} 10^{\prime \prime}$ & 170 & 77 \\
\hline
\end{tabular}

Table 3. The Hybrid III Family of Mannequins Data

\begin{tabular}{|cccc|}
\hline \multicolumn{4}{|c|}{ Probability of Compressive Injury } \\
Dummy & No Injury & Injury Likely & Unsurvivable \\
\cline { 3 - 4 } n Yr Old & $27 / 100$ & $9 / 100$ & $64 / 100$ \\
6 Yr Old & $32 / 100$ & $11 / 100$ & $57 / 100$ \\
Small & $29 / 100$ & $12 / 100$ & $59 / 100$ \\
Midsize & $45 / 100$ & $17 / 100$ & $38 / 100$ \\
Large & $49 / 100$ & $18 / 100$ & $32 / 100$ \\
\hline
\end{tabular}

Table 4. Probability of Injury Caused by Compression 


\begin{tabular}{|cccc|}
\hline \multirow{4}{*}{ Dummy } & \multicolumn{3}{l|}{ Probability of Tensile Injury } \\
\cline { 3 - 4 } No Injury & Injury Likely & Unsurvivable \\
\cline { 3 - 4 } 3 Yr Old & $39 / 100$ & $7 / 100$ & $54 / 100$ \\
6 Yr Old & $41 / 100$ & $11 / 100$ & $49 / 100$ \\
Small & $61 / 100$ & $12 / 100$ & $27 / 100$ \\
Midsize & $67 / 100$ & $11 / 100$ & $23 / 100$ \\
Large & $79 / 100$ & $7 / 100$ & $14 / 100$ \\
\hline
\end{tabular}

Table 5. Probability of Injury Caused by Tension

\begin{tabular}{|c|c|c|c|}
\hline \multicolumn{4}{|c|}{ Probability of Shear Injury } \\
\hline Dummy & No Injury & njury Likely & Unsurvivable \\
\hline $3 \mathrm{Yr} \mathrm{Old}$ & $24 / 100$ & $9 / 100$ & $67 / 100$ \\
\hline $6 \mathrm{YrOld}$ & $30 / 100$ & $10 / 100$ & $60 / 100$ \\
\hline Small & $35 / 100$ & $11 / 100$ & $55 / 100$ \\
\hline Midsize & $45 / 100$ & $15 / 100$ & $40 / 100$ \\
\hline Large & $48 / 100$ & $14 / 100$ & $38 / 100$ \\
\hline
\end{tabular}

Table 6. Probability of Injury Caused by Shear Force

\section{Discussion}

In each of the five cases, for the five different body types, data was compiled from previously published loading curves to determine what type of loading has the chance to cause a significant cervical spinal injury. Shear loading produces a much higher risk of injury on the neck at much lower loads when compared to compressive and tensile loading. If, for example, a compressive load were instantaneously applied to a mid size adult, but wasn't maintained, it takes approximately $3600 \mathrm{~N}$ to even enter the region that indicates there is a potential for significant injury. If that force were, however, a shear force, it only takes approximately $2900 \mathrm{~N}$ to enter that region (Figure 12). In each of the five body types, the safe and seriously injured regions are well defined. The middle regions, however are those most uninvestigated. They illustrate that injury is fairly likely to occur, but do not illustrate the severity of the injury depending on where one lies within that region. The probability definitions (Tables 4-6) supplement these risk injury curves by providing some scenarios in which various compressive, tensile and shear forces can cause significant injury.

It was important to recognize that not all body types are commonly subjected to forces of dangerous magnitude. For example, a 3 year old would most likely be secluded from 
situations that could cause him or her to endure such forces, unless the situation was unexpected such as an automobile accident. A large adult, however might perform everyday lifting and pushing tasks that make him or her more likely to encounter high compressive, tensile or shear forces. To take this form of exposure into consideration, Pert distributions (instead of normal distributions) were utilized in the Monte Carlo simulations. Pert distributions help identify associated risk and the likelihood of particular situations occurring, such as various types of people enduring any of a combination of applied loads. This made the results of the simulations more accurate and appropriate for this particular study.

Verifying these Monte Carlo simulations with experimental data was the next step with respect to this research. Cadaveric data was obtained from the literature to validate the accuracy of the Monte Carlo models [9]. As can be seen in Figure 12, the higher the applied force, the greater the probability of injury. Probability of injury was therefore plotted with respect to applied force for all five mannequin types under all three types of loading. A relationship was developed that indicated how probability of injury changed with respect to applied force. To relate the mechanisms of injury to a more common means of risk evaluation, equations were developed relating the applied force to the Abbreviated Injury Scale (AIS). The probability of achieving an injury with an AIS score between 2 and 5 can now be determined simply by knowing the applied force and using the following equations:

$$
\begin{aligned}
& P(A I S \geq 2)=\left(\frac{1}{1+e^{\left(2.056-1.1955\left(N_{i j}\right)\right.}}\right) \times 100 \% \\
& P(A I S \geq 3)=\left(\frac{1}{1+e^{\left(3.227-1.969\left(N_{i j}\right)\right.}}\right) \times 100 \% \\
& P(A I S \geq 4)=\left(\frac{1}{1+e^{\left(2.693-1.196\left(N_{i j}\right)\right.}}\right) \times 100 \% \\
& P(A I S \geq 5)=\left(\frac{1}{1+e^{\left(3.817-1.196\left(N_{i j}\right)\right.}}\right) \times 100 \%
\end{aligned}
$$

In the above equations, $\mathrm{N}_{\mathrm{ij}}$ refers to the normalized force. For the purposes of risk analysis, the normalized force is identified as the applied force, divided by the critical force, or forced deemed as having the minimum magnitude needed to induce injury.

Both cadaveric and mannequin data of applied force and the resulting probability of various AIS scores was plotted for each type of force. The results of these plots can be seen in Figures 13-15 for compression, tension and shear loading, respectively. In Figure 13, it can be seen that it takes approximately $4000 \mathrm{~N}$ of compressive force to generate a $30 \%$ risk of an AIS $\geq 2$ injury.

Comparatively, from Figure 15, it only takes approximately $3000 \mathrm{~N}$ of shear to generate that same $30 \%$ risk of an AIS $\geq 2$ injury. This again confirms that shear force poses a much higher probability of significant injury over the other types of forces at much lower magnitudes. 
This collection of plots sets a solid foundation for understanding what types of loading over what periods of time can injure someone, as well as the probability of someone experiencing different magnitudes of force over different time intervals. It is evident in the comparison of mannequin to cadaver data that mannequin testing does supply an accurate representation of a body's response to the various types of loading. Additionally it provides a more realistic means for studying a person's tolerance to force. The graphic schemes defined in this research have helped to identify the most common mechanisms of cervical spine injury.

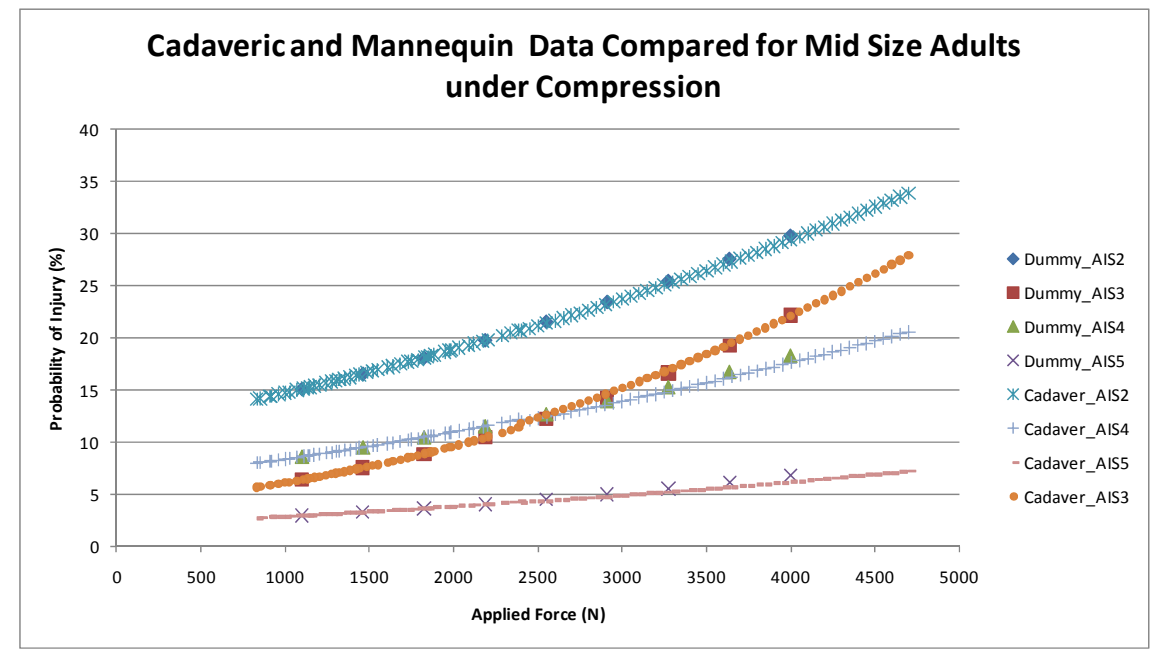

Figure 13. Figure 13: Cadaver and Mannequin Compression Loading Data

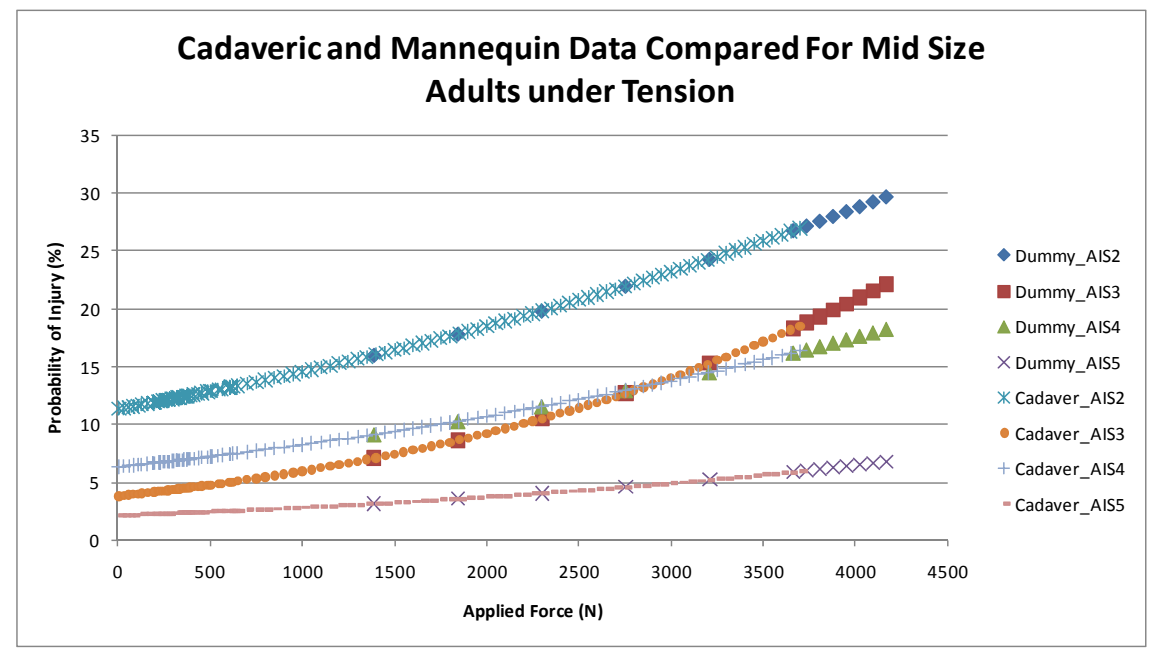

Figure 14. Figure 14: Cadaver and Mannequin Data for Tension Loading 


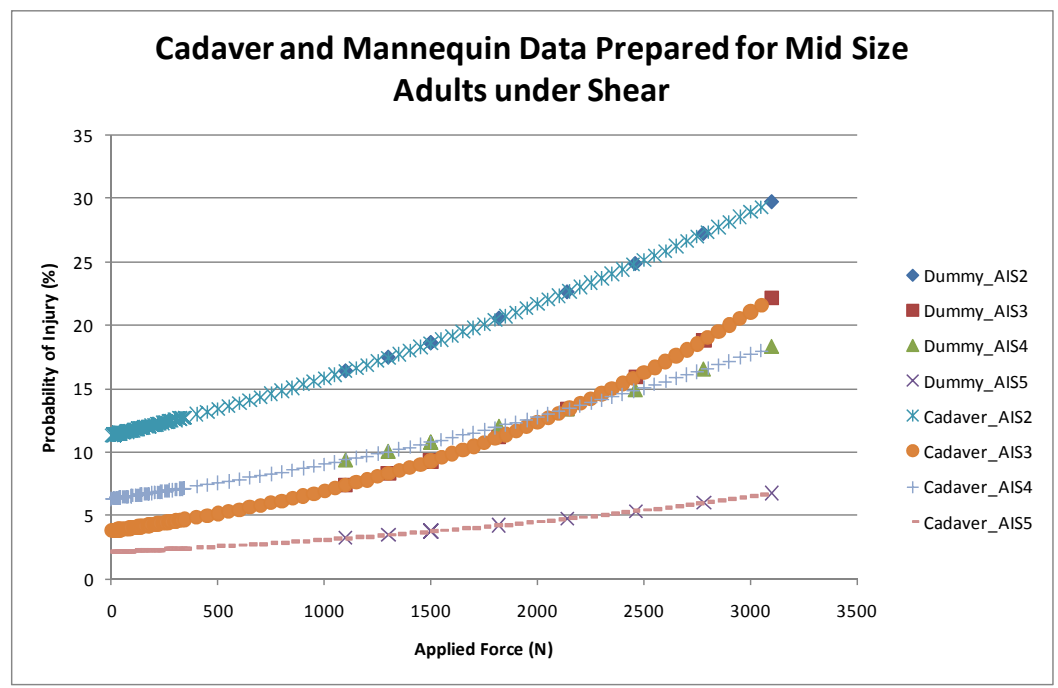

Figure 15. Cadaver and Mannequin Data for Shear Loading

\section{Conclusions}

This research presents a summary of various conditions under which the cervical injury takes place. The automobile accidents proved the most frequent cause of cervical injury in both Canada and the United States. Data from these countries was analyzed and envelopes where injury takes place graphically presented. Five different body types were used to help illustrate what types of loading are most likely to cause injury when they are applied over varying amounts of time. In all cases, shear loading causes the most risk for injury at smaller loads when compared to tensile and compressive loads. Although injury curves establish a good starting point for identifying risks, more research is needed to fully understand to what degree someone can be injured when exposed to these types of loads. Monte Carlo Method was used to simulate the probability of someone being exposed to different magnitudes of forces and different types of loading and their representative AIS scores in terms of new mathematical equations. These models were then developed to relate applied force to probability of injury at differing levels on the AIS. For all body types, the shear force mechanism posed the highest probability of injury, needing far less force to generate the potential for serious damage. It was also determined that the comparison of mannequin and cadaveric data, that mannequin testing provides an accurate means for assessing a person's probability of injury for all body types.

\section{Author details}

Mary E. Blackmore, Tarun Goswami* and Carol Chancey

Spine Research Group, Biomedical, Industrial and Human Factors Engineering Department, Wright State University, U.S.A.

${ }^{*}$ Corresponding Author 


\section{References}

[1] BrainandSpinalCord.org. Resources and Information for Brain and Spinal Cord Injury Survivors. Retrieved on December $9^{\text {th }}, 2010$

[2] Cheng R., Y. K. (1982). Injuries to the Cervical Spine Caused by a Distributed Frontal Load to the Chest. Proceedings of the 26th Stapp Car Crash Conference SAE Paper $821155,899-938$.

[3] Clemens HJ., B. K. (1972). Experimental Investigation on Injury Mechanisms of Cervical Spine at Frontal and Rear Front Vehicle Impacts. SAE Paper 720960 , 78-104.

[4] Doherty, B. E. (1993). A Biomechanical Study of Odontoid Fractures and Fracture Fixation. Spine , 18 (2), 178-184.

[5] Fielding JW., C. G. (1974). Tears of the Transverse Ligament of the Atlas. Journal of Bone and Joint Surgery , 56A (8), 1683-1691.

[6] Goel VK., W. J. (1990). Ligamentous Laxity Across the C0-C1-C2 Complex: Axial Torquerotation Characteristics Until Failure. Spine , 15, 990-996.

[7] Goldberg W., M. C. (2001). Distribution and Patterns of Blunt Traumatic Cervical Spine Injury. Annals of Emergency Medicine , 38 (1), 17-21.

[8] Lars, B. K. (2006). Acute Spinal Injuries: Assessment and Management. Emergency Medicine Practice , 8 (5), 1-28.

[9] Liu, Y. King, Krieger, K.W., Njus, G., Ueno, K., Connors, M.P., Wakano, K., Thies, D. Cervical Spine Stiffness and Geometry of the Young Human Male. Air Force Aerospace Medical Laboratory. Tulane University School of Medicine, New Orleans, LA. Approved for Public Release January 19, 1983.

[10] Maiman DJ., S. A. (1983). Compression Injuries of the Cervical Spine: A Biomechanical Analysis. Neurosurgery , 13 (3), 254-260.

[11] Mertz HJ., P. L. (1971). Strength and Response of the Human Neck. Proceedings of the 15th Stapp Car Crash Conference, 207-255.

[12] Myers BS., M. J. (1991). The Influence of End Condition on Human Cervical Spine Injury Mechanisms. Proceedings of the 35th Stapp Car Crash Conference, 391-400.

[13] Myers BS., M. J. (1991). The Role of Torsion in Cervical Spinal Injuries. Spine , 16 (8), 870-874.

[14] Nahum Alan M., M. J. (2002). Accidental Injury: Biomechanics and Prevention. New York: Springer.

[15] Pintar FA., Y. N. (1995). Cervical Vertebral Strain Measurements under Axial and Eccentric Loading. Journal of Biomechanical Engineering , 474-478.

[16] Portnoy HD., M. J. (1972). Mechanism of Cervical Spine Injury In Auto Accident. Proceedings of the 15th Annual Conference of the American Association for Automotive Medicine, 58-83.

[17] Reid DC., S. L. (1989). Spine Fractures in Winter Sports. Sports Medicine , 7 (6), 393-399.

[18] Sekhon, L. F. (2001, December 15). Epidemiology, Demographics and Pathophysiology of Acute Spinal Cord Injury. Spine, S2-12.

[19] Shea M., W. R. (1992). In Vitro Hyperextension Injuries in Human Cadaveric Cervical Spines. Journal of Orthopedic Research , 10 (6), 911-916. 
[20] Shield LK., F. B. (1978). Cervical Cord Injury in Sports. Physical Sports Medicine , 6, 321-326.

[21] Spinal Cord Injury: Facts and Figures at a Glance. (1999, April). Retrieved March 2010, from National Spinal Cord Injury Statistical Center: www.spinalcord.uab.edu

[22] Todinov, M. (2005). Reliability and Risk Models: Setting Reliability Requirements. Chichester, West Sussex, England: John Wiley \& Sons Ltd.

[23] Van Auken, Michael R., Zellner, John W. and Terry Smith. Development of an Improved Neck Injury Assessment Criteria for the ISO 13232 Motorcyclist Anthropometric Test Dummy. International Motorcycle Manufacturers Association, Switzerland. (2005) Paper No. 05-0227

[24] Wismans JS., S. C. (1983). Performance Requirements of Mechanical Necks in Laterial Flexion. Proceedings of the 27th Stapp Car Crash Conference 137.

[25] Yoganandan N., H. M. (1989). Epidemiology and Injury Biomechanics of Motor Vehicle Related Trauma to the Human Spine. Proceedings of the 33nd Stapp Car Crash Conference, $1102-1110$. 